\title{
AMADURECIMENTO DE MAMÃO FORMOSA COM REVESTIMENTO COMESTÍVEL À BASE DE FÉCULA DE MANDIOCA
}

\author{
Formosa papaya ripening with edible coating of cassava starch
}

\author{
Márcio Eduardo Canto Pereira ${ }^{1}$, Aurivan Santana da Silva², Aline Simões da Rocha Bispo ${ }^{3}$, \\ Djalma Barbosa dos Santos ${ }^{4}$, Silvia Barbosa dos Santos ${ }^{4}$, Vânia Jesus dos Santos ${ }^{3}$
}

\begin{abstract}
RESUMO
O mamão é fruta perecível, de vida útil pós-colheita curta. Novas tecnologias de conservação de produtos hortícolas com possibilidade de emprego em sistemas orgânicos têm sido desenvolvidas, a exemplo dos revestimentos comestíveis, que podem ser consumidos com o produto. Neste trabalho avaliou-se o amadurecimento de frutos de mamão Formosa 'Tainung 1' em temperatura ambiente, revestidos com película comestível à base de fécula de mandioca, que foi aplicada por meio de imersão dos frutos durante um minuto em suspensões de $1 \%, 2 \%$ e $3 \%$. No dia da aplicação do tratamento e a cada quatro dias, durante 12 dias, os frutos foram avaliados quanto à perda de massa, cor da casca, firmeza da polpa, sólidos solúveis (SS), acidez titulável (AT) e relação SS/AT. O experimento foi conduzido em delineamento inteiramente casualizado, em esquema fatorial 4 × 4 (\% de fécula na suspensão de tratamento x dias após o tratamento), com quatro repetições e um fruto por parcela. Os revestimentos comestíveis à base de fécula de mandioca a $1 \%$ e $3 \%$ prolongaram a vida útil pós-colheita de frutos de mamão Formosa 'Tainung 1' por quatro dias, sem afetarem a qualidade dos mesmos. Estes tratamentos retardaram o amadurecimento dos frutos, cujas alterações de cor da casca, firmeza da polpa, SS e AT foram significativamente mais lentas que os frutos não tratados.
\end{abstract}

Termos para indexação: Carica papaya, atmosfera modificada, pós-colheita.

\begin{abstract}
Papaya is a perishable fruit, of short shelf-life. New technologies of conservation of horticultural products with the possibility of being used in organic systems have been developed, such as the edible coatings that can be eaten with the product. In this work it was evaluated 'Tainung 1' Formosa type papaya ripening at room temperature and coated with edible cassava starch , which was applied by dipping the fruits during one minute in suspensions of $1 \%, 2 \%$ and $3 \%$. In the day of treatment application and every four days, during 12 days, fruits were evaluated for mass loss, skin color, pulp firmness, total soluble solids (SS), total titratable acidity (AT) and ratio (SS/AT). The experiment was conducted at a completely randomized design, in a 4 x 4 factorial scheme (\% starch in suspension $\mathrm{x}$ days after treatment), with four replications and one fruit per plot. The edible coatings of cassava starch at $1 \%$ and $3 \%$ extended the postharvest life of Formosa 'Tainung 1' papaya fruits for four days, without affecting their quality. These treatments delayed fruit ripening, whose skin color, pulp firmness, SS and AT changes were significantly slower than the ones of non-treated fruits.
\end{abstract}

Index terms: Carica papaya, modified atmosphere, postharvest.

\section{(Recebido para publicação em 31 de janeiro de 2006 e aprovado em 6 de julho de 2006)}

\section{INTRODUÇÃO}

Produtos agrícolas perecíveis, a exemplo das frutas tropicais, têm sua vida útil reduzida quando comparados aos duráveis (grãos e cereais), por apresentarem elevado teor de umidade, textura macia facilmente danificável e altas taxas respiratórias e de produção de calor. Essas características geram desvantagens quanto ao seu manuseio após a colheita, resultando em perdas decorrentes da falta de comercialização ou de consumo do produto em tempo hábil (CHITARRA \& CHITARRA, 2005).

Várias técnicas para o prolongamento da vida útil pós-colheita das frutas tropicais têm sido estudadas pela pesquisa. O uso da atmosfera modificada tem sido difundido por ser uma técnica simples de conservação, na qual normalmente empregam-se filmes plásticos que limitam as trocas gasosas e a perda de água para o ambiente, reduzindo o metabolismo do produto e prolongando sua vida pós-colheita (CHITARRA \& CHITARRA, 2005). No entanto, o uso de filmes plásticos pode ser limitante do ponto de vista ambiental e econômico.

Com a crescente demanda por produtos orgânicos, novas tecnologias adequadas a esses produtos também devem ser objeto de exploração pela pesquisa. $\mathrm{O}$ uso de revestimentos comestíveis para a conservação de produtos ao natural tem sido tema de alguns trabalhos. O revestimento é formado a partir de uma suspensão de um agente espessante, que após aplicação no produto forma

${ }^{1}$ M.Sc., Embrapa Mandioca e Fruticultura Tropical - Cx. P. 7 - 44380-000 - Cruz das Almas, BA - marcio@cnpmf.embrapa.br

${ }^{2}$ Agrônomo, Escola de Agronomia da Universidade Federal da Bahia/UFBA - 44380-000 - Cruz das Almas, BA.

${ }^{3}$ Estudante do curso de Agronomia, Escola de Agronomia da Universidade Federal da Bahia/UFBA - 44380-000 - Cruz das Almas, BA.

${ }^{4}$ Estudante do curso de mestrado em Agronomia, Escola de Agronomia da Universidade Federal da Bahia/UFBA - 44380-000 - Cruz das Almas, BA. 
uma película ao seu redor, agindo como barreira para trocas gasosas e perda de vapor d'água, modificando a atmosfera e retardando o amadurecimento do fruto. A fécula de mandioca é um dos agentes que podem ser usados para formação de revestimentos comestíveis, cujas características são boa transparência e boa resistência às trocas gasosas. Trabalhos científicos nesse sentido foram realizados com produtos hortícolas, a exemplo da goiaba (OLIVEIRA \& CEREDA, 1996) e do pimentão (VICENTINI et al., 1999).

O mamão é classificado como fruto climatérico, cujas características são de aumento da taxa respiratória (climatério), produção autocatalítica de etileno e alterações organolépticas substanciais durante o seu amadurecimento, tais como cor, sabor, amaciamento e produção de compostos voláteis aromáticos. Para o mamão "papaya" cita-se que a utilização da fécula de mandioca (2\%) não ocasionou efeitos nocivos, quando comparado ao tratamento com cera, além de ser efetivo na redução de perda de peso pelos frutos (CEREDA et al., 1992).

Este trabalho teve como objetivo avaliar o amadurecimento de frutos de mamão Formosa 'Tainung 1' em temperatura ambiente, revestidos com película comestível à base de fécula de mandioca.

\section{MATERIAL E MÉTODOS}

Frutos de mamão Formosa 'Tainung 1', oriundos da Embrapa Mandioca e Fruticultura Tropical, foram colhidos com os primeiros sinais de amarelecimento da casca (estádio 1 de maturação) e selecionados quanto ao tamanho. Após a seleção, os frutos foram lavados com detergente neutro e submetidos à imersão em solução de cloro a 100 ppm por três minutos. Após secagem ao ar, os frutos foram separados em grupos e submetidos aos tratamentos de imersão em suspensões de fécula de mandioca a $1 \%, 2 \%$ e $3 \%$ por um minuto. Essas suspensões foram preparadas adicionando-se a quantidade de fécula adequada em um litro de água sob agitação, aquecendo-se a suspensão até $70^{\circ} \mathrm{C}$. A fécula, de coloração branca e aparência limpa - sem resíduos, foi adquirida no Mercado Municipal de Cruz das Almas - BA, onde o produto é vendido a granel. Frutos do tratamento controle não receberam o revestimento. Após a aplicação dos tratamentos, o excesso da suspensão foi drenado em recipientes plásticos vazados e os frutos dispostos em bancadas para amadurecimento ambiente $\left(27^{\circ} \mathrm{C}\right.$ e $70 \%$ U.R.).

A cada quatro dias durante 12 dias os frutos foram avaliados quanto às seguintes variáveis: (a) perda de massa $(\%)$, obtida após tomada do peso da fruta no dia de aplicação do tratamento $(\mathrm{Pi})$ e no dia da avaliação $(\mathrm{Pf})$, pela seguinte fórmula: Perda de massa $(\%)=(\mathrm{Pi}-\mathrm{Pf}) / \mathrm{Pi}^{*} 100 ;$ (b) cor da casca, pela atribuição de notas de 1 a 5, de acordo com o amarelecimento da casca, estabelecido como base para os estádios de amadurecimento na classificação brasileira de mamão (CQH, 2003); (c) firmeza da polpa (Newtons - N), obtida com penetrômetro manual FT-327, efetuando-se duas leituras na polpa, em lados opostos, após a retirada da casca; (d) sólidos solúveis (SS), obtido por meio de leitura em refratômetro manual, a partir de duas gotas da polpa da fruta extraída e homogeneizada em centrífuga doméstica; (e) acidez titulável (AT), obtida por titulação com $\mathrm{NaOH} 0,1 \mathrm{~N}$ de $1 \mathrm{~g}$ de polpa homogeneizada diluída em $50 \mathrm{~mL}$ de água destilada até $\mathrm{pH} 8,1$; (f) relação SS/AT.

$\mathrm{O}$ experimento foi conduzido em delineamento inteiramente casualizado, em esquema fatorial 4 × 4 (\% de fécula na suspensão de tratamento $\mathrm{x}$ dias após $\mathrm{o}$ tratamento), com quatro repetições e um fruto por parcela. Os dados foram submetidos à análise de variância, aplicando-se o teste de Tukey a 5\% e regressão polinomial para os efeitos simples significativos de $\%$ de fécula e dias após o tratamento, respectivamente. Nos casos de interação significativa, foram realizadas análises de regressão a partir do desdobramento dos tratamentos com diferentes concentrações de fécula em cada tempo de avaliação, ajustando-se equações de até segundo grau. O programa SISVAR (FERREIRA, 2000) foi utilizado para a análise estatística dos dados.

\section{RESULTADOS E DISCUSSÃO}

Não houve efeito dos tratamentos para a variável perda de massa, embora os valores absolutos tenham revelado menor perda com o aumento da concentração da fécula na suspensão (Tabela 1), o que pode ser atribuído à provável redução na perda de água pelos frutos, gerada pelo aumento da espessura do revestimento.

TABELA 1 - Valores médios de perda de massa (\%) e relação SS/AT de frutos de mamão Formosa 'Tainung 1', revestidos com fécula de mandioca a $0 \%, 1 \%, 2 \%$ e $3 \%$, após 12 dias de armazenamento. Embrapa Mandioca e Fruticultura Tropical, Cruz das Almas, BA, 2005.

\begin{tabular}{ccc}
\hline \% fécula & Perda de massa $(\%)$ & Relação SS/AT \\
\hline 0 & $4,44 \mathrm{a}$ & $91,60 \mathrm{a}$ \\
1 & $4,26 \mathrm{a}$ & $96,23 \mathrm{a}$ \\
2 & $3,93 \mathrm{a}$ & $94,88 \mathrm{a}$ \\
3 & $3,88 \mathrm{a}$ & $117,38 \mathrm{~b}$ \\
\hline Média & 4,13 & 99,81 \\
C.V. $(\%)$ & 18,08 & 16,49 \\
\hline
\end{tabular}

Valores seguidos da mesma letra na coluna não diferem estatisticamente entre si pelo teste de Tukey ao nível de $5 \%$ de probabilidade. 
Houve interação significativa dos fatores para as variáveis cor da casca, firmeza da polpa, SS e acidez titulável - AT (Figura 1). Os revestimentos de 1\% e 3\% de fécula retardaram a pigmentação alaranjada da casca dos frutos em quatro dias: o controle atingiu a nota média de 4,7 aos oito dias e os frutos tratados atingiram as médias de 5,0 e 4,3 aos 12 dias, respectivamente (Figura 1A). No mamão ocorre a degradação da clorofila e a síntese de carotenóides na casca, sendo este último em menor proporção que o primeiro em frutos de 'Sunrise Solo' e 'Golden' (FONSECA, 2002). As notas médias para cor da casca obtidas neste trabalho indicam que houve a redução na degradação da clorofila na casca, mas sem prejuízo à coloração final dos frutos, quando da última avaliação.
A perda de firmeza dos frutos tratados com $1 \% \mathrm{e}$ $3 \%$ também foi reduzida em pelo menos quatro dias (Figura 1B). Aos oito dias após o tratamento, a firmeza da polpa destes frutos permaneceu alta $(133 \mathrm{~N})$, enquanto os frutos controle e com revestimento $2 \%$ já tinham sua firmeza da polpa reduzida para menos de $30 \mathrm{~N}$. Todos os frutos chegaram aos 12 dias com a firmeza próxima a $20 \mathrm{~N}$, considerada ideal para consumo por Bron et al. (2003) para o mamão 'Golden'. A maior firmeza notada nos frutos com revestimentos de $1 \%$ e $3 \%$ poderá garantir aos frutos melhor resistência a danos mecânicos durante o manuseio e, conseqüentemente, maior durabilidade. A observar-se pela coloração da casca e pela firmeza da polpa, o amadurecimento desses frutos foi acelerado nos quatro últimos dias de avaliação.
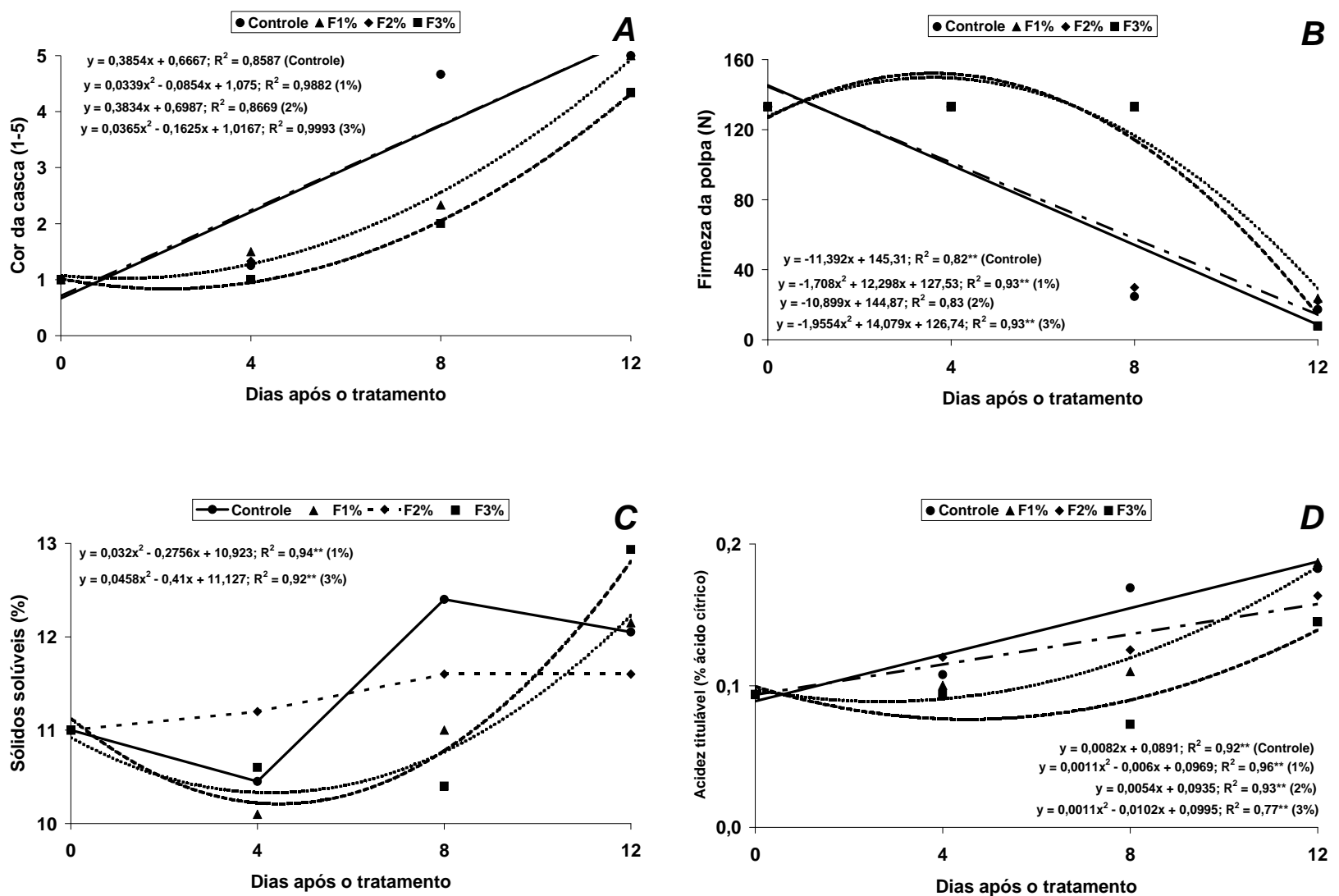

FIGURA 1 - Cor da casca (A), firmeza da polpa (B), sólidos solúveis (C) e acidez titulável (D) de frutos de mamão Formosa 'Tainung 1' submetidos ao tratamento com suspensão de fécula de mandioca a $0 \%$ (Controle), $1 \%, 2 \%$ e $3 \%$. Embrapa Mandioca e Fruticultura Tropical, Cruz das Almas, BA, 2005.

Ciênc. agrotec., Lavras, v. 30, n. 6, p. 1116-1119, nov./dez., 2006 
O teor de sólidos solúveis - SS (Figura 1C) e a acidez titulável - AT (Figura 1D) também foram outros dois parâmetros de qualidade que aumentaram mais rápido nos frutos controle. Outros trabalhos relatando valores para essas características mostram grande variação entre os resultados obtidos (FONSECA, 2002; MIRANDA et al., 2003), do modo ao observado neste experimento, porém com aumento significativo e diferenciado entre os tratamentos. $\mathrm{O}$ aumento no teor de sólidos solúveis pode ser atribuído ao acúmulo de açúcares e o aumento da acidez à formação do ácido galacturônico no processo de degradação da parede celular, processos que ocorrem durante o amadurecimento do mamão, ainda que em pequena escala (COSTA \& BALBINO, 2002). Tendo por base estes parâmetros de qualidade, nota-se que os tratamentos com os revestimentos de $1 \%$ e $3 \%$ foram eficientes em retardar o amadurecimento, atingindo os valores semelhantes aos dos frutos não tratados aproximadamente quatro dias após (Figuras 1C e 1D). Adicionalmente, a relação SS/AT somente foi alterada significativamente pelo tratamento com $3 \%$ de fécula (Tabela 1).

\section{CONCLUSÕES}

Frutos de mamão Formosa 'Tainung 1' tiveram sua vida útil pós-colheita prolongada em quatro dias com revestimentos comestíveis à base de fécula de mandioca a $1 \%$ e $3 \%$, sem terem sua qualidade prejudicada em função do retardamento do processo de maturação. Esse fato poderá refletir de modo positivo na comercialização do produto.

\section{AGRADECIMENTOS}

Os autores agradecem à FAPESB, ao CNPq e à CAPES, pela concessão de bolsas de iniciação científica e mestrado, respectivamente, e a Eugênio Ferreira Coelho, pela concessão dos frutos para a realização deste trabalho.

\section{REFERÊNCIAS BIBLIOGRÁFICAS}

BRON, I. U.; JACOMINO, A. P.; PINHEIRO, A. L.; KLUGE, R. A. Controle do amadurecimento de mamões 'Golden' com 1-metilciclopropeno e refrigeração. In: MARTINS, D. S. (Ed.). Papaya Brasil: qualidade do mamão para o mercado interno. Vitória: Incaper, 2003. p. 643-646.

CENTRO DE QUALIDADE EM HORTICULTURA. Programa Brasileiro para a Modernização da Horticultura. Normas de classificação do mamão. São Paulo: CQH/ CEAGESP, 2003. (Documentos, 25).
CEREDA, M. P.; BERTOLINI, A. C.; EVANGELISTA, R. M. Uso do amido em substituição a ceras na elaboração de filmes na conservação pós-colheita de frutos e hortaliças: estabelecimento de curvas de secagem. In: CONGRESSO BRASILEIRO DE MANDIOCA, 7., 1992, Recife. Resumos... Recife: Sociedade Brasileira de Mandioca, 1992. p. 107.

CHITARRA, M. I. F.; CHITARRA, A. B. Pós-colheita de frutos e hortaliças: fisiologia e manuseio. 2. ed. Lavras: UFLA, 2005. $785 \mathrm{p}$.

COSTA, A. F. S.; BALBINO, J. M. S. Características da fruta para exportação e normas de qualidade. In: FOLEGATTI, M. I. S.; MATSUURA, F. C. A. U. (Eds.). Mamão: pós-colheita. Brasília, DF: Embrapa Informação Tecnológica, 2002. p. 12-18. (Série Frutas do Brasil, 21).

FERREIRA, D. F. Análises estatísticas por meio do Sisvar para Windows versão 4.0. In: REUNIÃO ANUAL DA REGIÃO BRASILEIRA DA SOCIEDADE INTERNACIONAL DE BIOMETRIA, 45., 2000, São Carlos. Programa e Resumos... São Carlos: UFSCar, 2000. p. 255-258.

FONSECA, M. J. O. Conservação pós-colheita do mamão (Carica papaya L.): análise das cultivares 'Sunrise Solo' e 'Golden', sob controle de temperatura e de atmosfera. 2002. 177 f. Tese (Doutorado em Produção Vegetal) Universidade Estadual do Norte Fluminense, Campos dos Goytacazes, 2002.

MIRANDA, S. P.; ALBERNAZ, D. F.; FAGUNDES, G. R.; YAMANISHI, O. K. Efeito do tratamento hidrotérmico nas características físico-químicas e vida pós-colheita de mamões do grupo formosa. In: MARTINS, D. S. (Ed.). Papaya Brasil: qualidade do mamão para o mercado interno. Vitória: Incaper, 2003. p. 651-654.

OLIVEIRA, M. A.; CEREDA, M. P. Utilização de película de fécula de mandioca como alternativa à cera comercial na conservação pós-colheita de frutos de goiaba (Psidium guajava). In: CONGRESSO LATINO AMERICANO DE RAÍZES TROPICAIS, 1.; CONGRESSO BRASILEIRO DA MANDIOCA, 8., 1996, São Pedro. Anais... São Pedro: [s.n.], 1996. p. 225.

VICENTINI, N. M.; CASTRO, T. M. R.; CEREDA, M. P. Influência de películas de fécula de mandioca na qualidade pós-colheita de frutos de pimentão. Ciência e Tecnologia de Alimentos, Campinas, v. 19, n. 1, p. 127-130, 1999. 